\title{
Observations on the Ductility and Thermostability of Tungsten Processed from Micropowder by Improved High-pressure Torsion
}

\author{
Liang Chen, Li Ping, Tian Ye, Li Lingfeng, Xue Kemin, Zhao Meng
}

Hefei University of Technology, Hefei 230009, China

\begin{abstract}
Tungsten was subjected to severe plastic deformation at $440{ }^{\circ} \mathrm{C}$ using high pressure torsion (HPT) with an improved die-set. Microhardness measurements suggest an appreciable ductility level in tungsten after HPT with Vickers microhardness HV as high as 11 $500 \mathrm{MPa}$. Differential scanning calorimetry (DSC) analyses show that samples with less strain have a higher recrystallisation temperature (greater than $1450{ }^{\circ} \mathrm{C}$ ) than samples with more strain $\left(\sim 800{ }^{\circ} \mathrm{C}\right)$. X-ray diffraction analyses indicate increases in lattice strain up to $0.35 \%$, lattice parameter up to $0.3177 \mathrm{~nm}$ and dislocation density up to $2.4 \times 10^{15} \mathrm{~m}^{-2}$. The current study introduces the improved HPT process as an effective route for the production of ultrahigh strength $\mathrm{W}$ with significant ductility and specified thermostability.
\end{abstract}

Key words: severe plastic deformation; consolidation; ductility; thermostability; dislocation

Tungsten is widely used in many fields such as filaments, fusion reactors and military purposes. It possesses a high melting point, high erosion resistance and good thermal conductivity. However, tungsten is a very brittle metal with a high ductile-to-brittle-transition temperature (DBTT), which is influenced by parameters such as cold work, grain size and impurities ${ }^{[1,2]}$.

Recent studies on tungsten have shown that ultrafine grained (UFG) or nanocrystalline (NC) materials produced by severe plastic deformation (SPD) have properties that differ substantially from those of their coarse-grained (CG) counterparts $^{[3-5]}$. UFG/NC W, compared with conventional CG W, exhibits a higher flow stress, enhanced ductility, reduced strain-hardening capacity, and reduced strain-rate sensitivity.

High pressure torsion (HPT) is a method of SPD used to produce bulk nanostructured materials with grain sizes sometimes smaller than $100 \mathrm{~nm}^{[6]}$. This procedure results in unique mechanical properties such as increased hardness and considerable ductility ${ }^{[7]}$.
In the present study, W powder was subjected to HPT. The study had two main objectives: (i) to consolidate W powder directly using an improved HPT die-set and (ii) to produce tungsten with ultrahigh strength, considerable ductility and thermostability. Ductility was confirmed by observing the indentation impressions after the microhardness measurements using an optical microscope (OM) and scanning electron microscope (SEM). Thermostability was investigated using differential scanning calorimetry (DSC). The evolution of the microstructures during HPT was investigated through quantitative $\mathrm{X}$-ray diffraction (XRD) analysis.

\section{Experiment}

The W powder had a purity level of $99.9 \%$ and an average particle size of less than $5 \mu \mathrm{m}$. The morphology of the $\mathrm{W}$ powder is shown in Fig.1. HPT was conducted at $440{ }^{\circ} \mathrm{C}$ to consolidate the powder discs of $10 \mathrm{~mm}$ diameter and $1 \mathrm{~mm}$ thickness under the nominal pressure of $P=2,4$ GPa. Shear strain, $\gamma(\gamma=2 \pi r N / h$, where $r$ is the distance from

Received date: December 17, 2015

Foundation item: International Thermonuclear Experimental Reactor of China (2014GB1210001)

Corresponding author: Xue Kemin, Professor, School of Materials Science and Engineering, Hefei University of Technology, Hefei 230009, P. R. China, Tel 0086-551-62901368, E-mail: xuekm0721@sina.com

Copyright ( 2 2016, Northwest Institute for Nonferrous Metal Research. Published by Elsevier BV. All rights reserved. 
the disc centre, $N$ is the number of turns, and $h$ is the disc thickness), was introduced through rotations for either $N=$ 5,10 turns with a rotation speed of $\omega=0.67 \mathrm{r} / \mathrm{min}$.

A conventional HPT die-set is shown in Fig.2a. It is difficult to maintain the support in ideal coaxial rotation with reference to the plunger, so the clearance between the plunger/support and ring to consolidate $\mathrm{W}$ powder is difficult to design. If the clearance is too small, a tiny misalignment will cause interference between the plunger/support and the ring. The die will then be damaged after several turns. However, if the clearance is too large, the abrasion on the die from trimming will be considerable (because of the high hardness of W).

Therefore, the die-set has been improved as shown in the sketch in Fig.2b. In this structure, the ring has been replaced by a compressible gasket. This design provides two important advantages: (i) the off-axis fault tolerance of the support is increased significantly, thus decreasing the difficulty of HPT accordingly; and (ii) compression of the compressible gasket will exert extra pressure on the sample, and thus, ceteris paribus, the pressure on the sample will be greater than that in conventional HPT.

For development, disc samples were first polished to a mirror-like surface on both sides. Secondly, the Vickers microhardness was measured on the downward surface of a $4 \mathrm{GPa}$ sample and on both surfaces of a $2 \mathrm{GPa}$ sample every $1 \mathrm{~mm}$ from the centre using an applied load of $200 \mathrm{~g}$ for 20 $\mathrm{s}$ at four different radial directions. Thirdly, the ductility was investigated by observing the impression of the

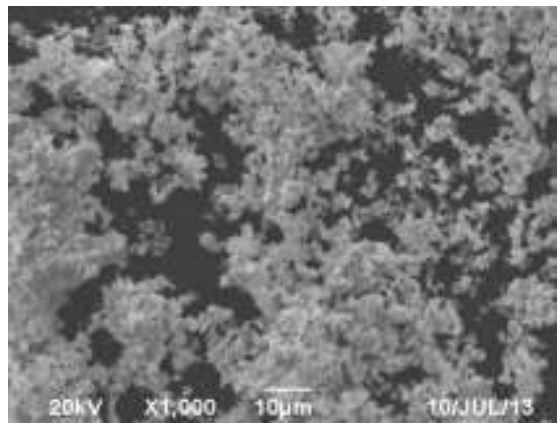

Fig.1 SEM morphology of W powder
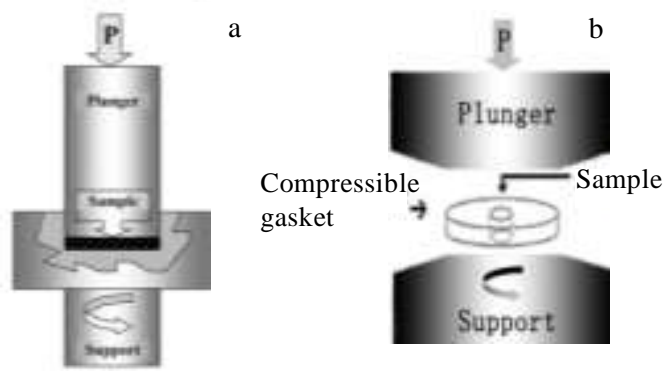

Fig.2 Sketches of conventional HPT (a) and improved HPT (b) microhardness indentations after testing at a load of $200 \mathrm{~g}$ or $2 \mathrm{~kg}$ and a loading time of $20 \mathrm{~s}$. Fourthly, DSC analysis was performed on the samples. The sample were heated under argon gas to $1450{ }^{\circ} \mathrm{C}$ at a rate of $20^{\circ} \mathrm{C} / \mathrm{min}$. Finally, $\mathrm{XRD}$ analysis was performed on the samples using $\mathrm{Cu} \mathrm{K} \alpha$ radiation at $40 \mathrm{kV}$ and $40 \mathrm{~mA}$ with a scanning step of $0.02^{\circ}$ and a scanning speed of $2 \% \mathrm{~min}$.

\section{Results and Discussion}

Fig.3 displays the hardness variation with distance from the disc centre after $2 \mathrm{GPa}, 5$ turns or $4 \mathrm{GPa}, 10$ turns. The microhardness increases with the increasing pressure, turns and distance from the disc centre. The saturation of the hardness appears in the $4 \mathrm{GPa}, 10$ turns disc sample at 3 $\mathrm{mm}$ from the disc centre. The microhardness on the bottom of the $2 \mathrm{GPa}, 5$ turns sample is higher than that on the top between the centre and $2 \mathrm{~mm}$ from the centre; however, the micro- hardness in the area from $2 \mathrm{~mm}$ to $5 \mathrm{~mm}$ is almost identical. The hardness HV level at saturation exceeds $12000 \mathrm{MPa}$ for the $4 \mathrm{GPa}, 10$ turns sample. Notably, these impressively high hardness levels are much higher than those of HPT-processed pure $\mathrm{W}^{[8,9]}$ and intermetallic-based nanocomposites ${ }^{[10]}$.

For a polycrystalline metal, microhardness can be quantitatively correlated with yield strength and grain size; i.e., a high microhardness value indicates a smaller grain size and higher yield strength. In turn, a high yield strength corresponds to a fine grain size, as determined by the conventional Hall-Petch relationship. The Hall-Petch relation for $\mathrm{W}$ in terms of Vickers hardness is ${ }^{[11]}$

$$
H=H_{0}+K_{\mathrm{H}} \cdot d^{-1 / 2}
$$

where, $H_{0}$ is $350 \mathrm{~kg} / \mathrm{mm}^{2}$, and $K_{\mathrm{H}}$ is $10 \mathrm{~kg} / \mathrm{mm}^{2} ; H=H_{\mathrm{V}} /$ 0.102. Using the data in Fig.3, we estimate the grain size of the $4 \mathrm{GPa}$ sample to be approximately $140 \mathrm{~nm}$ near the disk edge. This result indicates that the increased level of strain induced in the $\mathrm{W}$ by the higher pressure and the greater number of turns increases the grain refinement.

The presence or absence of cracking around the

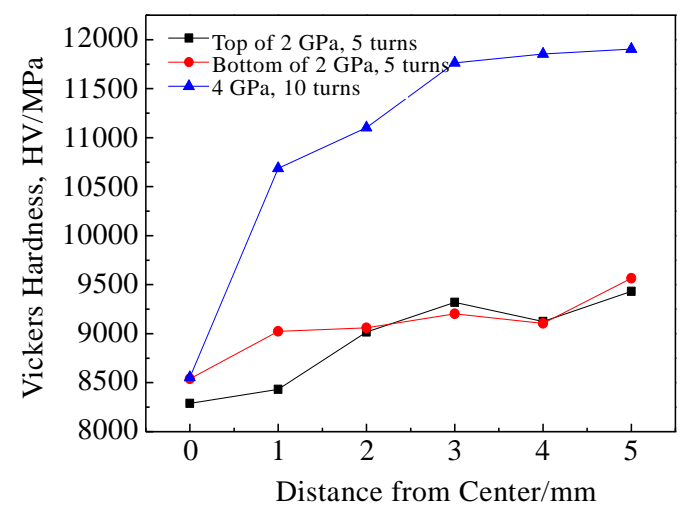

Fig.3 Variations of Vickers microhardness plotted along distance from disc centre for $\mathrm{W}$ 
indentation impressions developed during the microhardness testing may qualitatively reflect the toughness or ductility of the materials at the testing temperature ${ }^{[12]}$. For the UFG tungsten processed by HPT, no clear cracks are observed around the impression indented at room temperature, as shown in Fig.4, including a SEM image of a rectangular area in Fig.4b, which qualitatively suggests the ductile state of UFG tungsten. However, a plastic deformation area near the indentation impression is observed in Fig.4d (arrow) with no crack in the zoom image. This deformation area also suggests a certain plasticity in tungsten processed by HPT.

An empirical rule tells us that the DBTT of tungsten decreases monotonically with the strain induced during the plastic working ${ }^{[13,14]}$. A reasonable explanation of this phenomenon is that plastic deformation changes the grain shape and increases the grain boundary area, which will decrease the average concentration of impurities segregated to grain boundaries. However, the conventional methods of deformation, such as rolling and extrusion, cannot accumulate very high strain without reducing material size. An additional disadvantage of conventional methods is their limited ability to produce new high angle grain boundaries $^{[15,16]}$ that could further reduce impurity concentrations in the grain boundaries.

In this work, UFG tungsten processed by HPT exhibits a substantially reduced DBTT, possibly lower than room temperature. The HPT processing is indicated to be feasible to improve the toughness or ductility of the generally brittle tungsten. The improved toughness or ductility in the UFG tungsten is a combined result of fine grain size and high-energy GBs of non-equilibrium character ${ }^{[17]}$.

Fig.5 and Fig.6 show DSC profiles of tungsten processed by HPT and optical micrographs after DSC tests, respectively. An examination of Fig.5 indicates three important points:
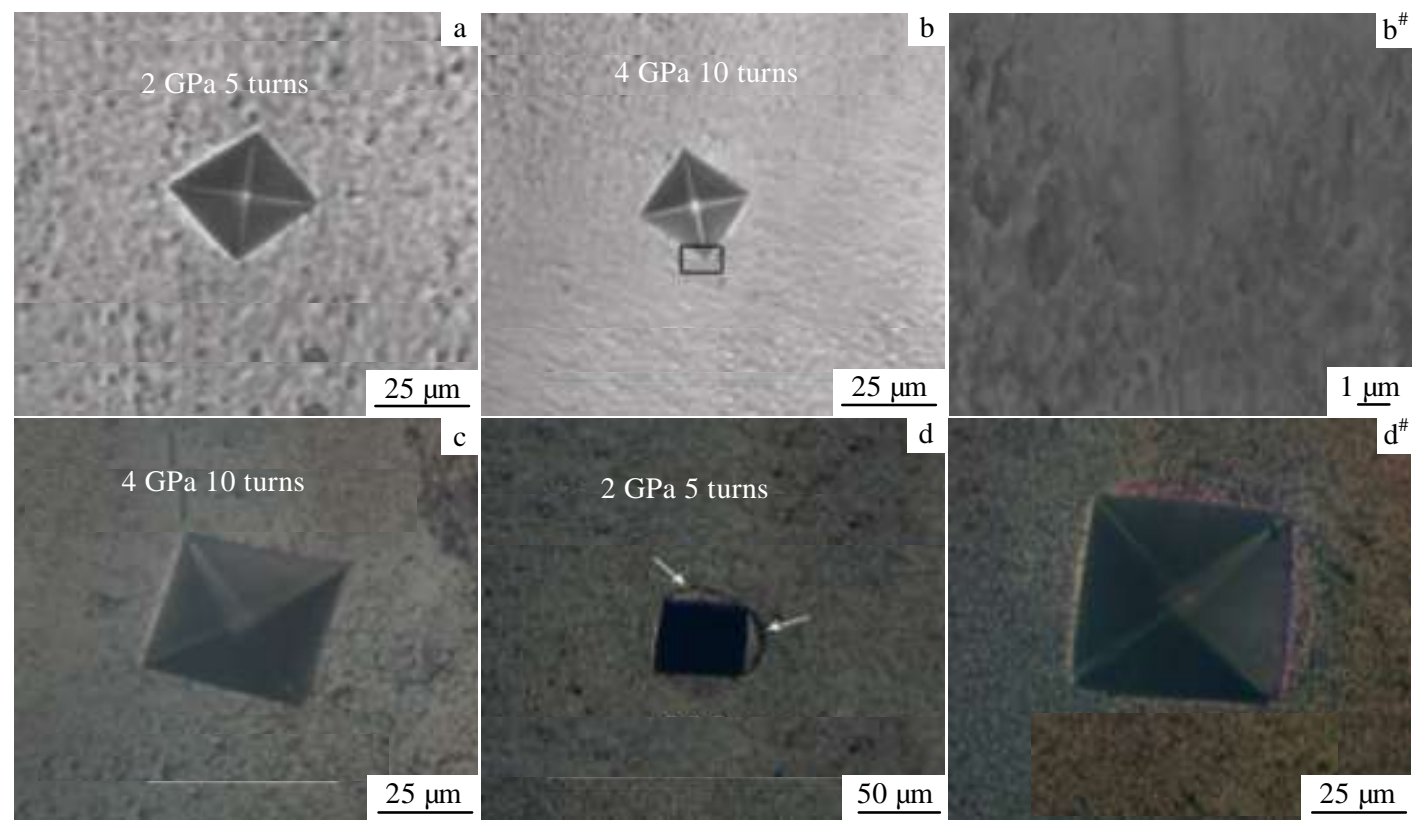

Fig.4 OM (a d) and SEM $\left(\mathrm{b}^{\#}, \mathrm{~d}^{\#}\right)$ images of impressions obtained during the microhardness measurement of tungsten: (a, b) $200 \mathrm{~g}$ force, (c, d) $2 \mathrm{~kg}$ force

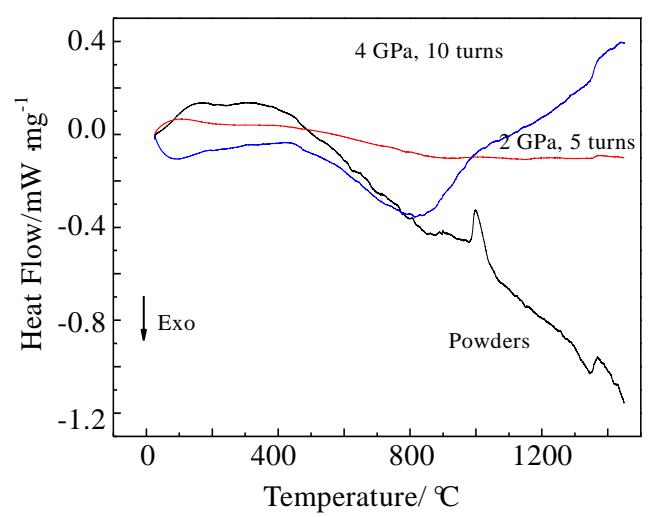

Fig.5 DSC profiles of tungsten processed by HPT (i) The absolute value of the heat flow of tungsten after HPT is significantly lower than the corresponding value for W powders. This result suggests a better thermostability of tungsten after HPT. Heat flow in DSC means extra thermal energy is absorbed or released by samples during the heating process compared to that absorbed or released by the standard substance. Thus, greater heat flow indicates more thermal reactions. As the DSC temperature is as high as $1450{ }^{\circ} \mathrm{C}$, which is comparable with the sintering temperature in the conventional process, the powders consolidate and cause a significant heat flow, whereas tungsten after HPT has a fine density and static recrystallization, which is the main reason for the heat flow. 
(ii) A minimal value can be observed in the curve of 4 $\mathrm{GPa}, 10$ turns, which is evidence of the recrystallisation temperature. In this study, samples were heated under argon gas to prevent oxidation. In addition, no phase change occurred during DSC, as will be demonstrated below by XRD. The $4 \mathrm{GPa}, 10$ turns sample undergoes full recrystallisation during DCS, which is consistent with Fig.6b, and the recrystallisation temperature is approximately $800{ }^{\circ} \mathrm{C}$.

(iii) The absolute value of the heat flow of the $2 \mathrm{GPa}, 5$ turns sample is lower than that of $4 \mathrm{GPa}, 10$ turns sample, with no minimal value in the DSC curve.

Fig.6a shows partial recrystallisation. These results indicate that the $2 \mathrm{GPa}, 5$ turns sample exhibiting less deformation has better thermostability than the $4 \mathrm{GPa}, 10$ turns sample exhibiting greater deformation. As one method of severe plastic deformation (SPD), HPT introduces high strain and corresponding high dislocation density into tungsten, as will be shown below, which will influence the thermostability of W. As tungsten is usually used at high-temperature, an appropriate HPT parameter is based on overall considerations that include both mechanical properties and thermostability.

XRD patterns of $\mathrm{W}$ are shown in Fig.7a for the powders and for the discs consolidated by HPT for $2 \mathrm{GPa}, 5$ turns and for $4 \mathrm{GPa}, 10$ turns. The peaks for the standard $\mathrm{Si}$ powders are evident in Fig.7b. An examination of Fig.7 reveals two important points:

(i) The full-width at half-maximum (FWHM) increases significantly with torsional strain when HPT is used. The peak broadening is an important evidence of the occurrence

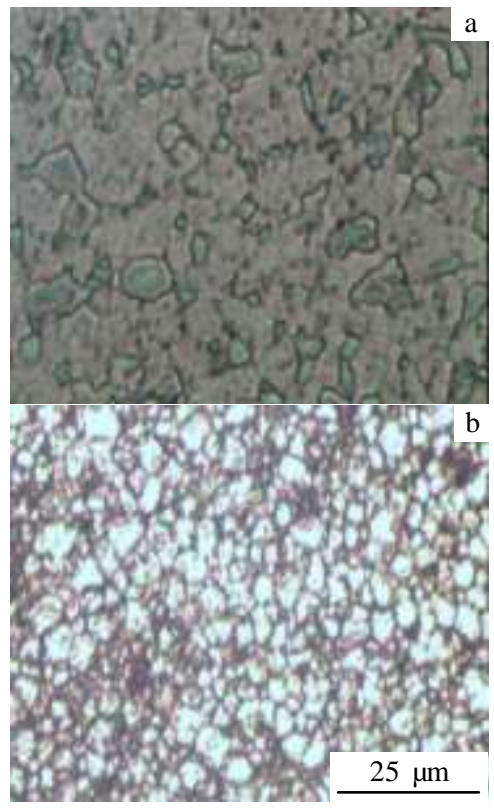

Fig.6 Optical micrographs of tungsten after DSC tests for $2 \mathrm{GPa}$, 5 turns (a) and $4 \mathrm{GPa}, 10$ turns (b) of lattice strain, dislocation generation and grain fragmentation during HPT processing. In the present study, the lattice strain and the dislocation density were calculated from the FWHM values using the Williamson-Hall method after the effect of the $\mathrm{K} \alpha_{2}$ radiation was removed and the inherent peak broadening caused by the radiation of the $\mathrm{X}$-ray diffractometer was subtracted. The lattice strain $\varepsilon$ and the dislocation density $\rho\left(\rho=14.4 \varepsilon^{2} / b^{2}\right.$, where $b$ is the Burgers vector) are plotted against the number of turns in Fig. $8 \mathrm{a}$ and $8 \mathrm{~b}$, respectively. Lattice strain and dislocation density increase with the torsional strain and reach levels as high as $\varepsilon=0.35 \%$ and $\rho=2.4 \times 10^{15} \mathrm{~m}^{-2}$ after $4 \mathrm{GPa}, 10$ turns, which are twice the values of $2 \mathrm{GPa}, 5$ turns. A high dislocation density indicates high stored energy ${ }^{[18]}$, which suggests low thermostability. Thus, tungsten with a high dislocation density is more likely to recrystallize and return to a steady state.

(ii) A close examination of the XRD patterns indicates that certain peak positions are shifted to somewhat lower or higher angles in the HPT-processed samples compared to their positions before HPT. Thus, the lattice parameters must change during the HPT processing. Here, the lattice parameter $(a)$ of $\mathrm{W}$ was determined using the Nelson-Riley extrapolation method and is plotted in Fig.8a. As shown in Fig.9, the lattice parameter increases with the number of
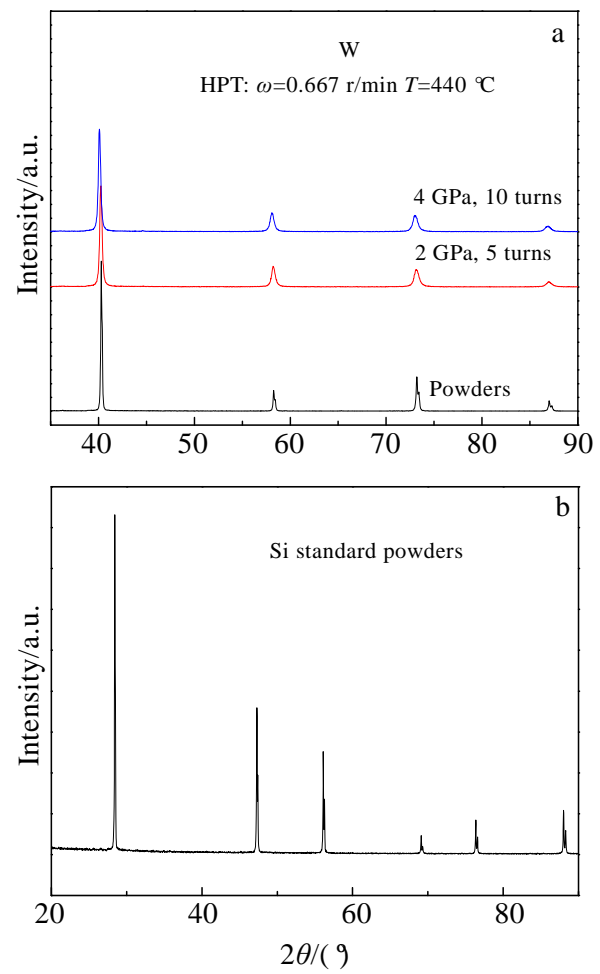

Fig.7 XRD patterns of $\mathrm{W}$ processed by HPT for $P=2 \mathrm{GPa}, N=5$ turns and $P=4 \mathrm{GPa}, N=10$ turns: (a) as-received powder and (b) standard Si powder 

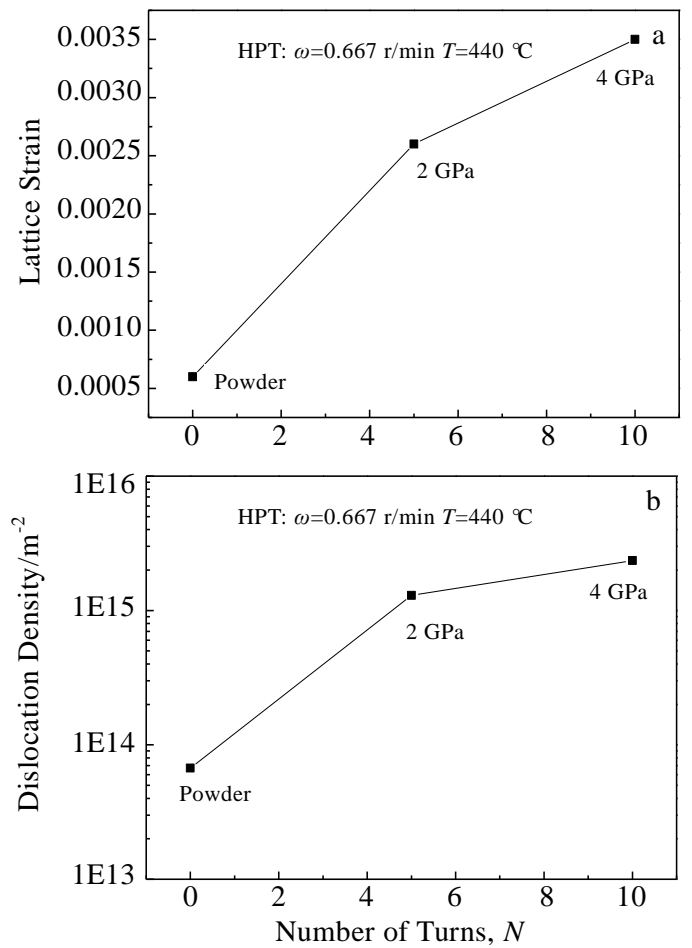

Fig.8 Variation of lattice strain (a) and dislocation density (b) in $\mathrm{W}$ grains as a function of number of turns for $\mathrm{W}$ processed by HPT, including as-received powder mixtures (the values were calculated from the XRD profiles using the Williamson-Hall method)

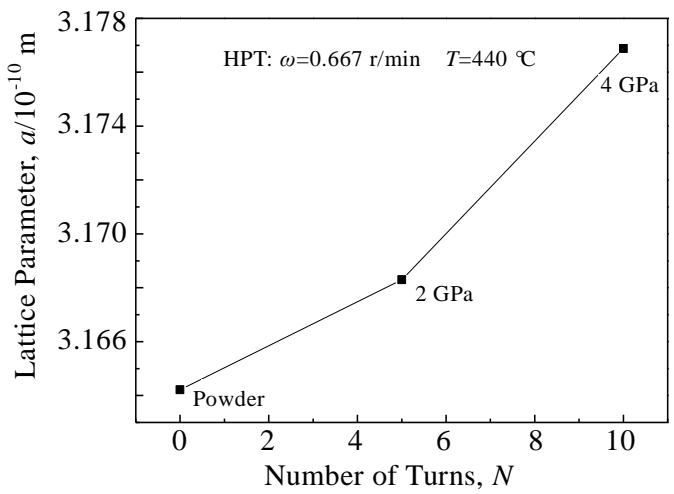

Fig.9 Variation of lattice parameters in $\mathrm{W}$ processed by HPT, including as-received powders (the lattice parameters were calculated from XRD profiles using the Nelson-Riley extrapolation method)

turns. High lattice strain or a large fraction of grain boundaries may influence the lattice parameters in tungsten, which also indicate a high stored energy. As the atomic distances $(R)$ are related to the lattice parameters ( $R=\sqrt{3} a / 4$ for bcc), increased lattice parameters indicate increased atomic distances, which may weaken the connection between $\mathrm{W}$ atoms. As a consequence, a lower thermostability in the $4 \mathrm{GPa}, 10$ turns sample was observed in DSC analysis.

\section{Conclusions}

1) Consolidated tungsten with highly strained grains, a large fraction of dislocation density and increased lattice parameters are produced from micropowder using the improved HPT process at $440{ }^{\circ} \mathrm{C}$.

2) The ultrahigh-strength tungsten (HV), $11500 \mathrm{MPa}$, with an appreciable ductility level is produced by introducing intense strain under high pressure through HPT processing.

3) The thermostability of tungsten is improved after HPT. However, the sample with less strain exhibits better thermostability than the sample with more strain. This phenomenon is caused by a synergistic effect of increased lattice strain, increased dislocation density and increased atomic distance.

\section{References}

1 Li Junqiang, Chen Wenge, Tao Wenjun et al. Rare Metal Materials and Engineering[J], 2012, 41(12): 2091

2 Faleschini M, Kreuzer H, Kiener D et al. Journal of Nuclear Materials [J], 2007, 367-370(26): 800

3 Wei Q, Ramesh K T, Ma E et al. Applied Physics Letters[J], 2005, 86(10): 101907

4 Wang Wenke, Song Yuepeng, Gao Dongsheng et al. Rare Metal Materials and Engineering[J], 2013, 42(S2): 301

5 Wei Q, Jiao T, Ramesh K T et al. Acta Materialia[J], 2006, 54(1): 77

6 Valiev R Z, Islamgaliev R K, Alexandrov I V et al. Progress in Materials Science[J], 2000, 45(2): 103

7 Valiev R Z. Advanced Engineering Materials[J], 2003, 5(5): 296

8 Wei Q, Zhang H T, Schuster B E et al. Acta Materialia[J], 2006, 54(15): 4079

9 Edalati K, Horita Z. Scripta Materialia[J], 2011, 64(2): 161

10 Edalati K, Toh S, Watanabe M et al. Scripta Materialia $[\mathrm{J}]$, 2012, 66(6): 386

11 Vashi U K, Armstrong R W, Zima G E. Metall Trans[J], 1970 1(6): 1769

12 Zhang Y, Ganeev A V, Wang J T et al. Materials Science and Engineering A [J], 2009, 503(1-2): 37

13 Greger M, Cìzek L, Widomska M. International Journal of Materials \& Product Technology[J], 2004, 157-158: 683

14 Gumbsch P. Journal of Nuclear Materials[J], 2003, 323(2): 304

15 Nes E. Progress in Materials Science[J], 1998, 41(3): 129

16 Doherty R D, Hughes D A, Humphreys F J et al. Materials Science and Engineering A[J], 1997, 238(2): 219

17 Gumbsch P, Riedle J, Hartmaier A et al. Science[J], 1998, 282(5392): 1293

18 Wang Y M, Xin R L, Wang B S et al. Materials Science and Engineering $A[\mathrm{~J}], 2011,528(6): 2941$ 


\title{
钨粉经高压扭转后韧性及热稳定性观察
}

\author{
梁 辰, 李 萍, 田 野, 李凌风, 薛克敏, 赵 蒙 \\ (合肥工业大学, 安徽 合肥 230009)
}

\begin{abstract}
摘 要: 采用高压扭转法, 在 $440{ }^{\circ} \mathrm{C}$ 对纯铇进行大塑性变形 (HPT)。硬度测试表明试样表面纯铇经高压扭转后硬度 HV 高达 $11500 \mathrm{MPa}$ 。 差热分析 (DSC) 结果表明等效应变较小的试样再结晶温度较高 (高于 $1450{ }^{\circ} \mathrm{C}$ ), 等效应变较大的试样再结晶温度较低 (约 $800{ }^{\circ} \mathrm{C}$ )。 XRD 分析结果表明试样晶格应变达 $0.35 \%$, 晶格常数达 $0.3177 \mathrm{~nm}$, 位错密度达 $2.4 \times 10^{15} \mathrm{~m}^{-2}$ 。高压扭转可以使纯铇在低温下实现固结 并具有高强度, 一定的㓞性和热稳定性。

关键词：大塑性变形；固结；㓞性；热稳定性；位错
\end{abstract}

作者简介：梁 辰，男，1988 年生，硕士，合肥工业大学材料科学与工程学院，安徽 合肥 230009, E-mail: 1c198806@126.com 